\title{
A Study on Influence of Motivation Factors on Employees Performance in Private Schools in Saudi Arabia
}

\author{
Mohammed Al Doghan1, Sukaina Albar² \\ ${ }^{1}$ Department of Management, King Faisal University, Al Ahsa, Saudi Arabia \\ ${ }^{2}$ Jinan Real Estate Company, Dammam, Saudi Arabia \\ Email:mdoghan@kfu.edu.sa
}

Received 9 October 2015; accepted 4 December 2015; published 7 December 2015

Copyright (C) 2015 by authors and Scientific Research Publishing Inc.

This work is licensed under the Creative Commons Attribution International License (CC BY). http://creativecommons.org/licenses/by/4.0/

(c) (i) Open Access

\section{Abstract}

The main purpose of the study is to assess the role of work motivation on employee's performance level in private schools in Saudi Arabia. The research aims to determine the factors that affect employees' motivation and its impact on job performance. In recent years, research showed that there was a direct relation between employees' motivation and business performance. In the field of education, which is a service business, it is very important for business profit and productivity to identify motivational factors that increase employees' performance. The research is based on a quantitative research method. The data in this research were mainly obtained by using questionnaires. Moreover, the research was conducted on a selection of private schools in Dammam that are located in the Eastern Province of Saudi Arabia. 150 employees were selected as a sample from three different schools. Only 119 questionnaires were suitable for a statistical analysis that equals to $79 \%$ of the total sample. The data were collected via a questionnaire covering four variables such as leadership style, organizational environment, salary, and stable future. The research tested the effect of these variables mentioned above on employees' performance.

\section{Keywords}

Motivation, Performance, Job, Business, Organizational Environment

\section{Introduction}

In Newton's law of physics by the famous Isaac Newton, physics primarily applies to lifeless and emotionless objects, but the same concept can be applied to human behavior, which can be observed in this research when 
motivational factors act as the external force, while human behavior acts as the object.

This research aims to examine and assess the significance of motivation on employee's level of performance, and the main motivational factors that affect employee's performance in the private education field in Saudi Arabia. What makes the subject of this research particularly relevant today is the dominance of the private sector over the public sector. In recent years, the private sector in Saudi Arabia is a booming business in terms of growth, investments, and employment. The economic policy makers in the Kingdom of Saudi Arabia realized the importance of the establishment of the Human Resources Development Fund, and its most important department of Employment, which coordinates the recruitment of Saudis and training. It is also responsible for studying applications for direct employment, the follow-up of new employees after they are hired, and the continuity of employment. The human resources development fund is concerned with monetary incentives, helping to raise the level of national salaries; in addition to, raising the aspirations and satisfaction of employees about material rewards (HRDF, The Guide Book, 2011) [1].

The purpose of the research is to identify, analyze, and provide an insight to the important motivational factors that affect employees in private schools in Saudi Arabia. The research will help to gain a better understanding of what drives employees' motivation in the private educational schools.

\section{Problem Statement}

Some organization can keep their employees motivated by increasing salaries, benefits, and rewards. But it is also important to understand that different employees are motivated differently. It is a complex situation exactly pin point what motivates employees. Cash is not the only motivational factor, and ignoring non-material factors could cause a lot of problems (Edlund, Nilsson, 2007) [2].

This research will attempt to define the important of motivational factors that affect employees' performance in the private educational field in Saudi Arabia. Moreover, the research will find whether the monetary and other material rewards are more important than non-monetary factors to motivate employees in private schools. The research will answer the question about what are the motivational factors that schools managers could use to improve and enhance employees' performance, and in turn increase schools productivity.

\subsection{The Research Purpose and Questions}

The research aims to identify and analyze the most important factors among motivational factors that motivate employees working in private schools in Saudi Arabia. The study will help to gain a better understanding about what precisely drives employees' motivation in the private educational field. The purpose of the research is to investigate what are the motivation factors that present as the most important factor among employees in private schools.

In order to serve the above purpose, the research will answer the following questions:

RQ1: What are the most important motivational factors that affect employees' performance in private school at Saudi Arabia?

RQ2: How can schools managers motivate their employees?

RQ3: How can the relationship between motivational factors and schools employees' performance be described?

RQ4: What are the desirable states of employees' motivation in private schools in Saudi Arabia?

\subsection{Research Objectives}

The main objective of the research is to determine and analyze the motivational factors that affect employees' performance in private schools in Saudi Arabia through achieving the following objectives:

1) To determine the main motivation factors that affect employees' performance in Saudi Arabia's private schools.

2) To clarify the important degree of the motivation factors to employees.

3) To find the best way to improve employees' performance in private schools.

4) To find if there is a relationship between motivational factors in private schools and the improvement of employees' performance.

5) To provide some recommendations and suggestions that might help to solve the research. 


\subsection{Research Hypothesis}

Based on the research problems and the literature review, the following research hypotheses will be examined to find whether there is a relationship between motivational factors and employees performance or not.

H0: There is no relationship between motivational factors and employees' performance.

H1: There is a positive relationship between leader ship style and employees’ performance.

H2: There is a positive relationship between Organizational Environment and employees’ performance.

H3: There is a positive relationship between salaries and employees’ performance.

H4: There is a positive relationship between Stable future and employees’ performance.

\subsection{The Significance of the Research}

The significance of the study is to improve the Saudi private educational field performance. This research will help private school managers understand the reasons for some of the choices made by employees. Also, it will help them to increase employees’ performance by affecting their decisions based on findings of the research.

\section{Literature Review}

The Kingdom of Saudi Arabia is one of the largest oil-producing countries; Saudi economy is primarily based on oil. The Saudi government playing a strong role to control the Saudi economy. In the recent years, Saudi economy start booming and come out with a lot of new important economic policies and decisions which support the Saudi community, looking for alternatives to reduce reliance on oil and strongly support the private sector, which relieves pressure on the public sector in terms of employment and saudization (Fox News, 2013) [3].

The government in Saudi Arabia strongly controls the most important and major economic activities. About $80 \%$ budget revenues comes from the oil sector, 45\% of GDP, and 90\% of export earnings according to International Monetary Fund Annual Report (IMF report, 2013) [4], which includes Saudi government to improve the private sector in order to interlarding its economy and to employ more Saudi nationals.

Saudi economic totally depending on public sector and government controls on the major commercial projects in the country that increase unemployment, which jumped from $10.5 \%$ end of 2009 to $12 \%$ at the end of 2012 , besides to the large number of students who graduate every year and looking for appropriate jobs in the market. According to a new report of the IMF more than 1.6 million young nationals will enter the workforce in the next five years in the Gulf countries include Saudi Arabia (Fox News, 2013) [3].

Decision-makers in Saudi Arabia start to focus on the private sector to ease the pressure on the public sector, create new opportunities for employment and stimulate the Saudi economy. Only 600,000 Saudis could find jobs in the private field by 2018 but around 1 million could find themselves without work. Saudization program, which is in the focus on the employment of Saudis, including approximately $50 \%$ of the total staff of any company. This decision had a major impact in stimulating the private field to be useful from the government support which aims to improve the private companies and help them to face the new economic requirements (Reuters, 2013) [5].

Managers at any organization face a lot of challenges. One of the most important challenges they face is how to motivate their employees to meet the organization needs and their own needs too, achieving the goals for both organization and staff (Tamila Arnania-Kepuladze) (2010) [6].

Work motivation is the first step in the process to achieve goals and enhance performance. Motivation creates the mental efforts that drive knowledge and skills. Without motivation, capable person could not work hard. Thus, motivational performance gaps exist whenever "people avoid starting something new, resist doing something familiar, stop doing something important and switch their attention to a less valued task, or refuse to 'work smart' on a new challenge and instead use old, familiar but inadequate solutions to solve a new problem” (Clark, 2003) [7].

Employees are the main asset of any organization that increased the interest about work motivation in the high global competition and growing industry (Bjorklund, 2001) [8]. Organization's success depends on employee performance, it is very important to have creative, innovative and commitmed employees. That is lead to stabilizing the economy and leads to improve life standards, increase salaries, and increase goods available. Some researcher argues that individual employee performance is important to all the society (Ndirtagu, 2013) [9]. Motivation has a positive effect on organizational commitment of employees (Mubbsher Khan and Hira Tahir 
Mansoor (2014) [10].

Feedback and rewards affect empowerment, financial feedback has positive infancy on perceived impact, but performance based on rewards has little significant and negative effects on self-determination (Hosain, 2014). Financial incentives and rewards motivate the employee to have a positive attitude at work, lead to work satisfaction, improve productivity and performance (Ekpudu and Ojeifo, 2014) [11].

Leaders who exhibit agentic qualities have been commonly and traditionally described as aggressive, ambitious, dominant, forceful, independent, daring, self-confident and competitive (Eagly and Johannesen-Schmidt, 2001) [12].

http://www.idra.org/IDRA_Newsletter/June_-_July_2005_Self___Renewing_Schools_Leadership_Accountabilit y/Review_of_Literature_on_Leadership/\#sthash [13]. A good portion of the studies on leadership styles has examined gender differences in leadership style when style is understood as relatively stable patterns of behavior that are manifested by leaders (Yoder) (2001) [14]. See more at:

http://www.idra.org/IDRA_Newsletter/June_-_July_2005.

There is a positive and significant relationship between financial incentives and employee commitment, increase in financial incentives will improve employee's performance. By satisfied employees' wants and desires organization can only increase employee loyalty (Syed Umair Abid and Nain Tara (2013) [15]. Environmental uncertainity, deined by Pfeffer and Salancik (1978) [16], refers to the degree to which futures states of the world cannot be anticipated and accurately predicted. Environmental uncertainty is problematic to an organization only when it involves an element critical to the organization. A stability involves maintaining the status quo or growing in a methodical but slow manner. The firm follows a safety oriented, status quo type strategy without effecting any major changes in its present operations.

\section{Research Methodology}

This research aims to understand and get a view on the motivational factors that affect employees' performance in private schools in Saudi Arabia. In order to answer the research questions and test the hypothesis, researcher collected data and information. The researcher designed survey questionnaire based on the hypothesis and literature reviews. 23 statements built in likert-scale style. Employees in three private schools in Dammam city were asked to give their agreeable degree about the statement to measure the degree of importance of the motivation factors under the study on job performance. The researcher chooses a sample of (150) employees represent the population of private school in Saudi Arabia based on random sampling technique. Data was collected and analyzed by using the Statistical Package for the Social Sciences (SPSS), and formulated by Multiple Linear regression testing to test the hypothesis and determine the relationship between the motivation factors and employees' performance which will guide to get the result and finding for the next chapter.

The survey questionnaire contains two sections. The first section consisted of 23 questions on 5 point on Likert-scale that related on motivational factors: Leadership style, Work Environment, Salaries and Future Stability. The second section, get the researcher general information about the sample. The employees in three schools in Dammam city were asked to rate statements about questions on a Likert scale from 1 to 5 , where 1 means strongly agree, 2 means agree, 3 means neutral, 4 means disagree and 5 indicates the strongly disagree with the statement. The questionnaire for the survey included 23 questions which largely based on extensive study of literature review. The number of questionnaires used for analysis equaled to (119), this mean that (79\%) from the total distributed questionnaires entered the analysis.

\section{Results}

\subsection{Demographic Variables of Sample}

Three demographic variables were included in this research (Age, Education Level, Experience years). The results represent a distribution of the sample according to a demographic variable. Result show that there were (61) responses of employees between (20 - 30) years of age their age reached (51\%) as a percentage of "Age” classes while only (8) responses were found in "more than 50 years of age” class with (7\%). (9\%) employees from (41 $50)$ years and (33\%) from 31 to 40 years. As we can see the highest range of employees age was between (20 30) then between (31 - 40) which mean almost 84\% form school employees was young employees. (73\%) of the sample have College degree. This percentage made this class the highest in educational level demographic vari- 
able; where, the smallest one was the class where the sample response had "Secondary school” with percentage equal to (2\%). The largest number of responses had experience "from 1 - 3 years" with (47\%) as a percentage, while (18\%) of employees had an experience "from 4 - 6 years". And only (24\%) from them their experience less than 1 year.

Table 1 given below is about "Leadership Style" scale. The highest mean in the table was (3.9160) and a standard deviation of (0.88853) to "An effective manager is the most important factor that improves my performance", this mean is in the first rank when compared with other items. The second highest mean to "A democratic boss directly affects my performance" which equal to (3.5546) and standard deviation (1.02260). These results made it in the second rank. The smallest mean (3.1429) belong to the statement "My manager's behavior directly affects my work" with a standard deviation of (1.24387) and in the (7th) rank.

\subsection{Organizational Environment}

Main motivation, factor Organizational Environment was measured by (6) items. The descriptive statistics of “Organizational Environment” and its items in Table 2.

Table 2 is about "Organizational Environment" scale. The highest mean of its items was (3.9412) and a standard deviation of (0.88580) to "Good maintenance of the building and facilities make me improve my work performance", this made it in the first rank when compared with other items. The second highest mean to "My office design affects my performance" which equal to (3.8160) and standard deviation (0.88753); these results made it in the second rank. The smallest mean (3.4454) belong to the statement "School location and environment is an important factor that improve my performance” with a standard deviation of (1.23300) and in the (6th) rank.

Table 1. Leadership style. Descriptive statistics of leadership style.

\begin{tabular}{cccc}
\hline Item & Statement & Mean & Stander deviation \\
\hline $\mathbf{1}$ & My manager's behavior directly affects my work & 3.1429 & 1.24387 \\
$\mathbf{2}$ & Good relationships between me and my bosses affect my job performance & 3.4958 & 1.20644 \\
$\mathbf{3}$ & I work harder when my bosses encourage me & 3.3109 & 1.11802 \\
$\mathbf{4}$ & Uncomfortable relationship with my boss decreases my performance & 3.4706 & 1.17764 \\
$\mathbf{5}$ & An effective manager is the most important factor that improves my performance & 3.9160 & 0.88853 \\
$\mathbf{6}$ & A domineering boss directly affects my performance & 3.4370 & 0.94455 \\
$\mathbf{7}$ & A democratic boss directly affects my performance & 3.5546 & 1.02260 \\
\hline
\end{tabular}

Table 2. Organizational environment. Descriptive statistics of organizational environment.

\begin{tabular}{cccc}
\hline Item & Statement & Mean & Stander deviation \\
\hline $\mathbf{1}$ & Comfortable working conditions make me increase my work performance & 3.4958 & 1.20644 \\
$\mathbf{2}$ & Good maintenance of the building and facilities make me improve & & 0.88580 \\
& my work performance & 3.9412 & 1.20644 \\
$\mathbf{3}$ & Good lightning, low noise levels, suitable temperature and & 3.4958 & 0.88753 \\
$\mathbf{4}$ & ventilation affect my job performance & 3.8160 & 1.23300 \\
$\mathbf{5}$ & My office design affects my performance & 3.4454 & 1.02260 \\
\hline
\end{tabular}




\subsection{Salary and Benefits}

The highest mean of its items was (3.9328) and a standard deviation of (0.88997) to "Steady income is the only reason that makes me work", this made it in the first rank when compared with others items. The second low highest means to "Financial incentives and rewards improve my performance" and "Money alone is not enough to satisfy me" which equal to (3.5546) and standard deviation (1.02260); these results made it in the second rank. The smallest mean (3.3958) belong to the statement "Promotions and salary rise make me work harder" with standard deviation of (1.20544) and in the (5th) rank.

\subsection{Stable Future}

The highest mean of its items was (3.9160) and a standard deviation of (0.88853) to "Feeling that I have a stable financial future make me improve my job performance", this made it in the first rank. The second highest mean to "Job security positively affects my performance" which equal to (3.5546) and a standard deviation (1.02260); these results made it in the second rank. The smallest mean (3.4958) belong to the statement "Seeing my future job position make me improve my work performance" with standard deviation of (1.20644) and in the (4th) rank.

The main research hypotheses examined are following:

H1: There is a positive relationship between leadership style and employee performance in private schools at Saudi Arabia at $(\alpha=0.05)$.

Simple regression is used to test this hypothesis. The final results help to fit the relationship between independent variable (job performance) and dependent variable (Leadership Style) was significant according to significant level (sig $=0.002<0.05$ ), while the increasing degree in Leadership Style will increase job performance by $(B=0.127)$. That means accept $(\mathrm{H} 1)$ hypothesis: there is positive relationship between Leadership Style and job performance in private school in Saudi Arabia.

H2: There is a positive relationship between Organization Environment and employee performance in private schools in Saudi Arabia at $(\alpha=0.05)$.

The final results shows that the relationship between the independent variable (job performance) and the dependent variable (Organization Environment) was not significant according to significant level (sig $=0.644>$ 0.05), That mean hypothesis (H2) was rejected.

H3: There is a positive relationship between salaries and employee performance in private schools in Saudi Arabia at $(\alpha=0.05)$.

The final results show that the relationship between the independent variable (job performance) and the dependent variable (salaries) was significant according to significant level (sig $=0.006<0.05$ ), while the increasing degree in salaries will increase job performance by $(B=0.103)$. That means accepting $(\mathrm{H} 3)$ : there is positive relationship between salaries and job performance in private school in Saudi Arabia.

H4: There is a positive relationship between Stable future and employees' performance in private schools in Saudi Arabia at $(\alpha=0.05)$.

The final results show that the relationship between the independent variable (job performance) and the dependent variable (Stable future) was not significant according to significant level (sig $=0.836>0.05$ ), That mean hypothesis (H4) was rejected.

\section{Discussion}

The researcher had expectation based on previous studies about motivational factors that affect employees in private schools. The literature reviews shows that there is a significant relationship between motivational factors and employees' performance in general; in addition to, the positive relationship of the specific motivational factors of the study (Leadership style, Organization environment, Salary and Stable future) and performance. It was expected that financial incentives represented by salaries had the major impact on employees' performance in private schools. Factors like leader ship style, work environment and stable future had a lower impact on employees' performance.

The results from the questionnaires showed that leader ship style represented by management style and attitude with employees had a higher level of importance to employees in schools under the study. In addition, the largest number of respondents had experience from 1 to 3 years corresponding to $47 \%$ of the total sample. On 
the other hand, $73 \%$ of the total sample had College degrees who were between the ages of 20 and 30 years old.

The result showed that there is a positive relationship between leadership style and employees' performance $($ sig $=0.002)$. Additionally, salary had a high degree of importance right after leadership style $(\operatorname{sig}=0.006)$. A number of the responding employees indicated that steady income is the only reason that leads them to work.

The null hypotheses was rejected which stated that there is no relationship between motivational factors and employees' performance. Hypotheses (H1) and (H3) which tests the relationship between leader ship style and employees' performance and between salaries and employees' performance was accepted .While hypotheses (H2) and (H4) which tests the relationship between organizational environment and employees' performance, and between stable future and employees' performance was rejected with $(\operatorname{sig}=0.644)$ and $(\operatorname{sig}=0.836)$ when $\alpha=$ 0.05 .

Owners of private schools could motivate their employees by focusing on these factors, employing good and effective managers, apply democratic leadership style, increase employees' salaries, and focus on incentive reward and promotions to make jobs in private schools more attractive, and improve their employees' performance.

The result helped to answer the research questions whether money was the most important motivational factor that affect employees in private schools in Saudi Arabia. The result showed that leadership style was the most important motivational factor that affected employees in private schools in Saudi Arabia, where money was the next factor in importance for employees in private schools.

The next question was concerned with how school managers motivate their employees. The result showed that managers could find appropriate style of leadership to deal with employees, and improve the relationship between them and their employees in away could affect their behaviors at work, and their job performance. Also, mangers should focus on incentive rewards and promotions, and improve their reward system.

The third question asked how the relationship between motivational factors and school employees' performance can be described. The hypothesis testing answered this question, and showed a positive relationship between leadership style and salaries, and improvement in performance. An increase by one unit in the leadership style factor could increase performance by 0.127 . While an increase by one unit in the salary factor could increase performance by 0.103 . On the other hand, the result did not show any significant relationship between the two motivational factors of organizational environment and stable future on job performance.

The last question was concerned with the desirable state of employees' motivation of private school in Saudi Arabia. Based on the result, employees showed high level of importance to the factors of leader ship style and salaries, and how an improvement in these factors could motivate employees, improve their performance at school, and make private schools more attractive for them.

\subsection{Conclusions}

The main results that were provided to solve the research problem, answered the questions, and tested the hypotheses were:

1) The importance level of leadership style in private school in Saudi Arabia was high.

2) The importance level of salaries in Saudi Arabia in private schools was high.

3) There was a significant positive effect of leadership style on employees' performance in private school in Saudi Arabia at a significance level of $(\alpha=0.05)$.

4) There was an insignificant positive effect of organizational environment on employees' performance in private schools in Saudi Arabia at a significance level of $(\alpha=0.05)$.

5) There was a significant positive effect of salaries on employees' performance in private schools in Saudi Arabia at a significance level of $(\alpha=0.05)$.

6) There was an insignificant negative effect of stable future on employees' performance in private schools in Saudi Arabia at a significant level of $(\alpha=0.05)$.

From the above results, the most important conclusions can be drawn as follows:

1) There was a high level of importance of factors leadership style and salaries for employees in private schools in Saudi Arabia.

2) There was a significant positive relationship between the leadership style and salaries factors and employees' performance in private schools in Saudi Arabia.

3) There was a positive and an insignificant relationship between organizational environment factor and em- 
ployees' performance in private school in Saudi Arabia.

4) There was a negative and an insignificant relationship between the stable future factor and employees' performance in private school in Saudi Arabia.

\subsection{Recommendation}

To motivate employees and improve their performance at work in private schools in the kingdom of Saudi Arabia especially those working in the city of Dammam, mangers should focus on some motivational factors such as leadership style and salary. In addition, a lot of motivational factors have an influential effect on performance of employees as evident in the previous studies.

The research found that employing an affective leader could enhance the work performance. The leadership style can also have an effect on employees' performances by making them feel comfortable, and influence their work directly.

On the other hand, the Human Resources Development Fund realized the importance of financial incentive, which led them to support private schools directly in increasing teachers' salaries, and determining a minimum limit for Saudi employees' wages. Moreover, school owners should participate and offer higher salaries to their employees in order to achieve a higher job performance.

The research showed that good work conditions and environment such as appropriate equipment, space, heating, colors, lighting and transportation could improve employees' performance. In addition, the results of this research found that leadership style was the most important motivational factors that affected employees in private schools in Saudi Arabia.

Based on the research results, the researcher presented some of recommendations to the private school managers to improve their employees' performance:

Private school mangers in Saudi Arabia should increase salaries for their employees, and provide benefits to attract good employees while retaining the old and highly experienced employees.

Private school owners in Saudi Arabia should enroll in leadership skills workshops and selectively recruit their leaders.

Private school mangers in Saudi Arabia should create new strategies and improve their rewards system.

Private school mangers in Saudi Arabia should effectively implement team work, and find new strategies to apply democratic leadership style, give employees a chance to participate, and understand employees' needs and desires.

Private school owners in Saudi Arabia should hire managers, who are open minded, well-educated and open to change.

Private school mangers in Saudi Arabia have to improve the work environment, transportation, offices, and all the items that could affect employees' performance.

\subsection{Future Prospect of the Study}

This research aims to find the most important motivational factors that affect employees working in the private schools in Saudi Arabia. Motivation is very complex, and it is hard to answer all the questions with a sample clearly defined answers as showing in the theoretical part of the research.

In the future, an increase in the sample size could increase the ability to generalize the findings. Also, future researches can cover more motivational factors that affect the employees' performance in private school in Saudi Arabia. For future studies, researcher need more time to cover more motivation factors in a larger number of samples than what was included in this research. In addition, future researches can cover other large cities like Riyadh and Jeddah to aid generalization of results. Also, a comparative study can be conducted to compare the results from respondents in private school in one period of time, and again a few years after to identify whether motivational factors actually have an effect on employees' performance and behavior.

\section{References}

[1] Human Resource Development Fund (2011) The Guide Book, Saudi Arabia. www.HRDF.org.sa

[2] EFI, The Economic Research Institute, Stockholm.

[3] Fox News (2013) Saudi Arabia Needs Private Field Growth to Stem Youth Unemployment, Business Leaders Say. 
http://www.foxnews.com/world/2013/12/03/saudi-arabia-needs-private-field-growth-to-stem-youth-unemployment-bus iness/

[4] Informational Brochure (2012) Survey Questionnaire Design.

[5] Reuters (2013) IMF Urges Saudi Arabia to Boost Private Field Jobs. http://www.arabianbusiness.com/imf-urges-saudi-arabia-boost-private-field-jobs-529294.html

[6] Arnania-Kepuladze, T. (2010) Gender Stereotypes and Gender Feature of Job Motivation: Differences or Similarity? Problems and Perspectives in Management, 8.

[7] Clark, R.E. (2003) Fostering the Work Motivation of Individuals and Teams. Performance Improvement, 42, 21-29. http://dx.doi.org/10.1002/pfi.4930420305

[8] Bjorklund (2001) Defense Mechanisma and Morlaity: A Link between Isolation and Moralization. Scandinavian Journal of Psychology, 41, 55-62. http://dx.doi.org/10.1111/1467-9450.00171

[9] Ndirtagu (2013) Employee Motivation and Performance as a Catalyst for Organizational Growth. Academic Journal of Interdisciplinary Science, 2.

[10] Khan, M. and Mansoor, H.T. (2014) Factors Influencing Motivation Level of Academic Staff in Education Field of Pakistan. European Centre for Research Training and Developmental, 1, 41-48.

[11] Ekpudu and Ojeifo (2014) Financial Incentives and Rewards on Employee Motivation in Nigerian Electricity Distribution Company. International Knowledge Sharing Platform, 6.

[12] Eagly, A.H. and Johannesen-Schmidt, M.C. (2001) The Leadership Style of Women and Men. Journal of Social Issues, 57, 781-787. http://dx.doi.org/10.1111/0022-4537.00241

[13] IDRA News Letter (2005) Inter Cultural Development Research Association. Self Renewing Schools, Teaching Quality, Access and Success.

[14] Yoder, J.D. (2001) Making Leadership Work More Effectively for Women. Journal of Social Sciences, 57, 815-828. http://dx.doi.org/10.1111/0022-4537.00243

[15] Abid, S.U. and Tara, N. (2013) The Impact of Rewards on Employee Motivation, the Mediating Role of Office Design: Empirical Evidence from Hotel Industry of Pakistan. IOSR Journal of Business and Management, 7, 46-51. http://dx.doi.org/10.9790/487X-0764651

[16] Pfeffer, J. and Salancik, G.R. (1978) The External Control of Organizations: A Resource Dependence Perspective, New York. 